\title{
The lived experience of men with erectile dysfunction was reflected in the themes of loss and being alone with it
}

\author{
Pontin D, Porter T,McDonagh R. Investigating the effect of erectile dysfunction on the lives of men: a qualitative research \\ study. J Clin Nurs 2002;11:264-72.
QUESTION: What are the issues facing men who live with erectile dysfunction (ED), particularly in their relationships with women partners and in their interactions with the wider community?

\section{Design \\ Qualitative study.}

\section{Setting}

United Kingdom.

\section{Participants}

A convenience sample of 9 men (age range 28-72 y) who were selected from new general practitioner (GP) referrals to a district general hospital and a specialist neurology clinic.

\section{Methods}

Men participated in semistructured indepth interviews
Source of funding: no external funding.

For correspondence: Dr D Pontin, Faculty of Health and Social Care, University of the West of England,

Bristol, UK.

David.Pontin@uwe.ac.uk that were audiotaped, transcribed, and analysed using an iterative process to generate categories and themes.

\section{Main findings}

2 main themes, loss and being alone with it, emerged. These 2 themes were connected via the meta-categories making sense of it, telling other people, and place of sex in the relationship.

\section{COMMENTARY}

This qualitative study by Pontin $e t$ al identifies and explores issues facing men who live with ED. Research that focuses on patients' viewpoints, such as this study, helps providers to better understand how patient level of functioning affects quality of life, ${ }^{1}$ to design and evaluate treatment modalities, to develop care plans that address specific patient identified needs, and to make appropriate referrals when needed.

Pontin et al identified 2 limitations of their study. Firstly, the study explored only the men's concerns, and it is likely that their partners may have different insights into the effects of ED on their relationship. Secondly, the study included only a small sample of men, and findings may differ for older or younger men, gay men, and men with different ethnic and socioeconomic backgrounds. Participants were men who sought treatment, but the reasons for seeking treatment were not clearly identified. The relation of the interview statements with the identified themes of loss and being alone with it were somewhat casually generalised in describing cause and effect.

A paucity of data exists on men's needs related to ED, including psychological, social, sexual, and patient care concerns. ${ }^{2}$ The study by Pontin et al identifies the need for further research on the effect of ED on manhood and fertility, the age and social background of men living with ED, decision making on treatment options, sources of information about treatment, relation between love and sex, and preferences related to treatment provider.

The findings emphasise the need to routinely include sexuality in community and hospital based nursing assessments. This requires a professional approach that offers respect for the individual and maintains confidentiality. Pontin et al stress the importance of making educational materials available to provide unbiased information about ED and its treatment to help patients make informed treatment choices.

JoAnn Mick, RN, MSN, MBA, AOCN Doctoral Student and Nurse Manager Texas Woman's University and MD Anderson Cancer Center Houston, Texas, USA

1 Litwin MS. Examining health-related quality of life in men treated for prostate cancer. World J Urol 1999;1 17:205-10.

Steginga SK, Occhipinti S, Dunn J, et al. The supportive care needs of men with prostate cancer (2000). Psychooncology 2001;10:66-75.
The theme of loss was related to a sense of manhood: "How can I be a man if I can't maintain or have erections?" Men referred to a hierarchy of signs that confer manhood (with erections at the top, followed by penile sensation, desire for sex, and ejaculations), and gauged the seriousness of their ED by comparing it with this hierarchy. They generally believed there was a lack of public acknowledgement about how common ED was, which they attributed to the pressure put on men by men to define their manhood in terms of sexual activity (eg, bragging). The sense of loss was also indicated by the process of making sense of $i$. Men talked about knowing and not knowing what caused their ED, postulating reasons including physical "malfunctions" and psychological problems (eg, work pressure). Men seemed uncertain whether their ED was permanent or temporary, in part, because of the gradual onset of symptoms. They were also unsure about what was normal for their age. Men $>60$ years of age said that they did not discuss sex openly with their partners because they were embarrassed, and their partners also felt embarrassed or at fault. Men $<60$ years of age, however, talked about their partners' acceptance of their ED and of still being in love. They discussed their ED and how to manage it with their partners. Men's uncertainty was also indicated in the process of finding a solution. Most were looking for a "cure" but did not expect to find one. A solution was seen as an intervention to produce and maintain erections. Men anticipated physical rather than psychological interventions (eg, counselling or hypnosis), which were primarily seen as supplements to physical interventions. The place of sex in the relationship varied. Some saw sex as an indicator of their love for their partners and worried that their partners might think they didn't love them anymore; others saw it as an added bonus to their love. Most men spoke of having sexual desires for their partners. They were concerned about meeting their partner's sexual needs, and talked about women wanting and preferring penetration.

The second theme, being alone with it, reflected the difficulties of telling others about their ED. In terms of telling other people, most men had only discussed their ED with their GP or a hospital physician. Disclosure of ED to health professionals (men or women) was not a problem for many men, who saw professionalism as a means of ensuring a sympathetic and confidential hearing. Some older men, however, had difficulties disclosing to either male or female health professionals. In some instances, the problem was identified when they consulted with their GP on another health matter.

\section{Conclusions}

The lived experiences of men with erectile dysfunction focused on 2 themes: loss and being alone with it. The meta-categories of making sense of it, telling other people, and the place of sex in the relationship linked the 2 themes. 